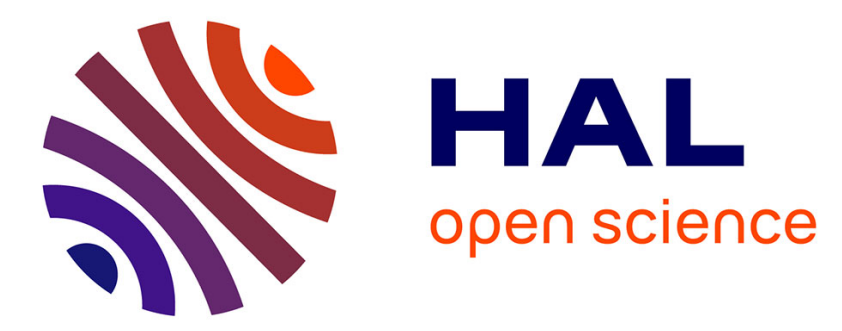

\title{
Boat borne radar mapping versus aerial photogrammetry and mobile laser scanning applied to river gorge monitoring
}

\author{
Marion Jaud, R. Rouveure, L. Moiroux Arvis, P. Faure, M.O. Monod
}

\section{To cite this version:}

Marion Jaud, R. Rouveure, L. Moiroux Arvis, P. Faure, M.O. Monod. Boat borne radar mapping versus aerial photogrammetry and mobile laser scanning applied to river gorge monitoring. Open Journal of Remote Sensing and Positioning, 2014, 1 (1), pp.48-63. hal-01139877

\section{HAL Id: hal-01139877 \\ https://hal.science/hal-01139877}

Submitted on 8 Apr 2015

HAL is a multi-disciplinary open access archive for the deposit and dissemination of scientific research documents, whether they are published or not. The documents may come from teaching and research institutions in France or abroad, or from public or private research centers.
L'archive ouverte pluridisciplinaire HAL, est destinée au dépôt et à la diffusion de documents scientifiques de niveau recherche, publiés ou non, émanant des établissements d'enseignement et de recherche français ou étrangers, des laboratoires publics ou privés. 


\title{
Boat-borne Radar Mapping Versus Aerial Photogrammetry and Mobile Laser Scanning Applied to River Gorge Monitoring
}

\author{
M. Jaud*, R. Rouveure, L. Moiroux-Arvis, P. Faure, M-O Monod,
}

Irstea, UR TSCF, 9 av. Blaise Pascal CS 20085, F-63178 Aubire, France

*Corresponding author: marion.jaud@irstea.fr

\begin{abstract}
:
River monitoring is an important component of sustainable management and preservation of water resource. Surveys have to be regularly performed. In this context, an alternative surveying procedure using a boat-borne radar is presented. This method is compared to two other techniques: infrared aerial photogrammetry and mobile laser scanning in order to assess their convenience to delineate the stream channel. As in steep-sided river valleys the delineation of the stream channel is particularly complex, the study focuses on two reaches of respectively $23 \mathrm{~km}$ and $2 \mathrm{~km}$ long, along the Ardche River (France) where the three techniques have been put to the test. Some specific situations such as effects of the overhanging cliffs have been taken into account to complete the study. Finally a comparison of the adequacy of the systems with respect to the conditions of use, cost of equipment, operational costs and data volume was carried out.
\end{abstract}

Keywords:

Mobile Laser Scanning; NIR Orthophotography; Radar mapping; River Gorge; Sream Channel delineation.

\section{INTRODUCTION AND BACKGROUND}

Rivers may be both waterways, source of water production, of energy, or areas for leisure activities. But, as rivers naturally tend to respond to any changes, they require a continual monitoring. In a perspective of sustainable management of fluvial ecosystems and water resources, lots of governmental organizations are interested in river monitoring [1]. They turn their attention to fluvial preservation, development and dynamics restoration, as well as crisis management, studying causes and impacts of floods or low water level.

As riverbanks are changing environments, surveys have to be frequently performed in order to update geomorphological maps and databases or official documents as, for example, cadastral records. Riverbanks position may also be used as inputs in hydrodynamics numerical models. Traditional surveying methods generally are theodolite or GPS surveys [2,3]. But these methods are very time-consuming and can capture only a small portion of a river. They are also unsuitable for steep-sided reaches of river or 
riverbanks covered with vegetation. More recently, the evolution of emerging technologies, sensors, platforms and algorithms has promoted the development of remote sensing of rivers, as described in [4]. Indeed, remote sensing can provide continuous coverage at different resolutions and scales. The survey device can be static or loaded on mobile platforms such as satellites, aircrafts or drones.

Satellite and aerial imagery [5], LiDAR [6, 7], or Synthetic Aperture Radar [8] offer the possibility of covering large areas. But, as mentioned by [9], aerial or satellite approaches involve a limited flexibility and they are very expensive. The acquisition parameters are not defined by the user, so they may be not appropriate for the study. Furthermore, the riverine canopy can be so thick that it is impossible to map the river width from aerial data. Alternative photogrammetric methods are developed, like oblique imagery [9] or small drone flying below the canopy [10]. Now, in-situ surveys may also be performed by field-based laser scanning. Terrestrial Laser Scanners (TLS) provide high-quality 3D models of the geomorphology [11, 12]. These studies only concern spatially-limited areas. [13, 14] report that boat-based Mobile Laser Scanner (MLS) allow surveying of larger reaches than an approach with TLS.

But the aforementioned methods are confronted problems of meteorological conditions, lighting conditions, occlusion of tree canopy, etc. In addition, as GNSS systems are at risk of signal degradation or even signal masking caused by man-made or natural obstructions, partial or total loss of tracking [15] and possible positioning errors can occur in river gorge. To supplement the conventional surveying techniques and overcome some of their limitations, a new alternative surveying procedure is proposed: radar acquisition from a little boat sailing down the river. Indeed, microwave radar systems allow rapid collection of data and overcome the limitations of vision-based sensors affected by ambient lighting conditions or mist $[16,17]$. Therefore, radars seem to be able to complement the other techniques, helping to solve some of the problems of remote sensing acquisition in fluvial context. So as to be easily loaded on the boat, the radar system must also be small-sized. Irstea (French National Research Institute of Science and Technology for Environment and Agriculture) has developed Pelican radar associated with a specific mapping algorithm, called R-SLAM.

The main objective of this research is to determine to what extent this technique is suited to the survey of riverbanks, especially in steep-sided rivers. In steep-sided river valleys, the delineation of the stream channel is especially complex, because of difficult access, GPS signal losses, overhanging effects of light and shadow, obstruction by the canopy. In this context, three techniques have been compared: i) Pelican radar mapping, ii) infrared aerial photogrammetry and iii) mobile laser scanning. They have been put to the test along two reaches, respectively $23 \mathrm{~km}$ and $2 \mathrm{~km}$ long, of the rocky gorges of the Ardèche River (France). Comparing their advantages and drawbacks, this study aims to assess the convenience of either device to delineate the stream channel.

\section{METHODOLOGY}

\subsection{Study Area}

The Ardèche river (Ardèche and Gard, France) is a tributary of the Rhâne river, forming a canyon from Vallon Pont D'Arc to Sauze (Figure 1 a). Most of this area is governed by a nature reserve and has already been widely studied, particularly because of the variable flood regime [18-20]. The Ardèche drains an area of $2350 \mathrm{~km}^{2}$, crossing a deep granitic valley, then basaltic and schist formations. Finally, from Vallon Pont d'Arc, it runs with a gentle slope within a canyon hollowed out in a calcareous plateau. The surrounding cliffs are more than $200 \mathrm{~m}$ high (Figure 2).

At the beginning of the canyon, a natural famous arch, the "Pont d'Arc" (about $60 \mathrm{~m}$ wide and $54 \mathrm{~m}$ high) spans the river, resulting from a meander cut off. This arch and the steep cliffs have been considered 


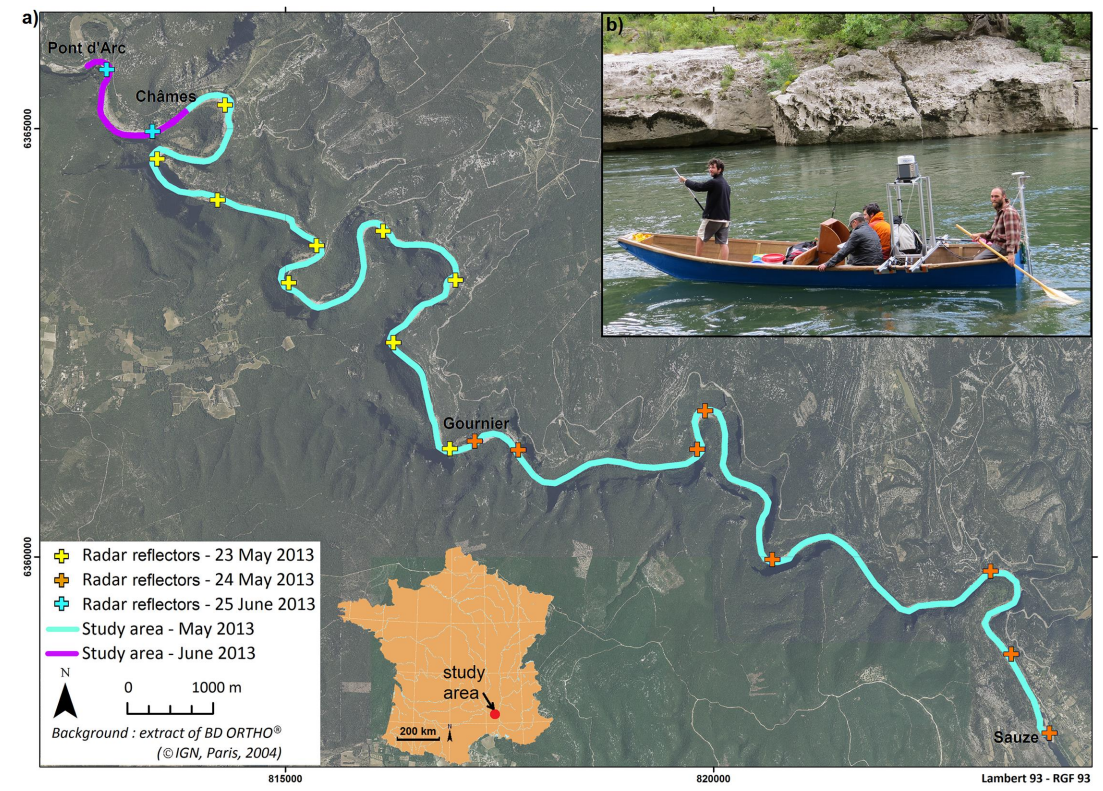

Figure 1. Geographical context of the two surveys. The first survey (Châmes to Sauze) outlined in blue is $23 \mathrm{~km}$ long. The second survey (Pont d'Arc to Châmes) depicted in violet is $2 \mathrm{~km}$ long. The positions of the radar reflectors are represented by blue, yellow and orange crosses. b) Typical boat of the Ardèche River used for the survey with the radar fastened on its gantry frame

as interesting elements in order to test the three surveying techniques.

\subsection{Arranging of the Surveys}

The first radar survey took place on the 23 and 24 May 2013, on a $23 \mathrm{~km}$ long reach running from Châmes to Sauze (Figure 1 a and Figure 2). A total of 17 radar reflectors, represented by crosses on Figure 1 a, have been erected on all along the reach, preferentially near the meanders. They are made of $34 \mathrm{~cm} \times 34 \mathrm{~cm} \times 47 \mathrm{~cm}$ metallic trihedral reflectors. Their positions were measured by a ProFlex@500 GNSS (Global Navigation Satellite System) receiver and then post-processed. The accuracy of positioning is above $8 \mathrm{~cm}$ horizontally and $5 \mathrm{~cm}$ vertically. Pelican radar was fastened on an adjustable gantry frame, loaded on a typical boat of the Ardèche River (Figure $1 \mathrm{~b}$ ). The boat was also equipped with another GNNS receiver so as to record the trajectory. Because of the cloud cover, it was not possible to perform a photographic survey over the zone at the same date as the radar survey. On the 27 May 2013, an aircraft flew over the zone, taking infrared photographs from whom orthoimages and a DEM (Digital Elevation Model) were produced.

The second radar survey took place on the 25 June 2013. In this experiment, Pelican radar was paired with a mobile laser scanning system. Previously scheduled on the 22 May 2013, this survey had to be postponed since the important flow discharge prohibited the navigation. Data have been collected from the natural arch of Pont d'Arc to Châmes, over a $2 \mathrm{~km}$ long reach (Figure $1 \mathrm{a}$ ). Considering the length of this reach, only two radar reflectors have been dropped off. Two laser point clouds of the Pont d'Arc have been collected by stationary laser scanning from the riverbanks. 


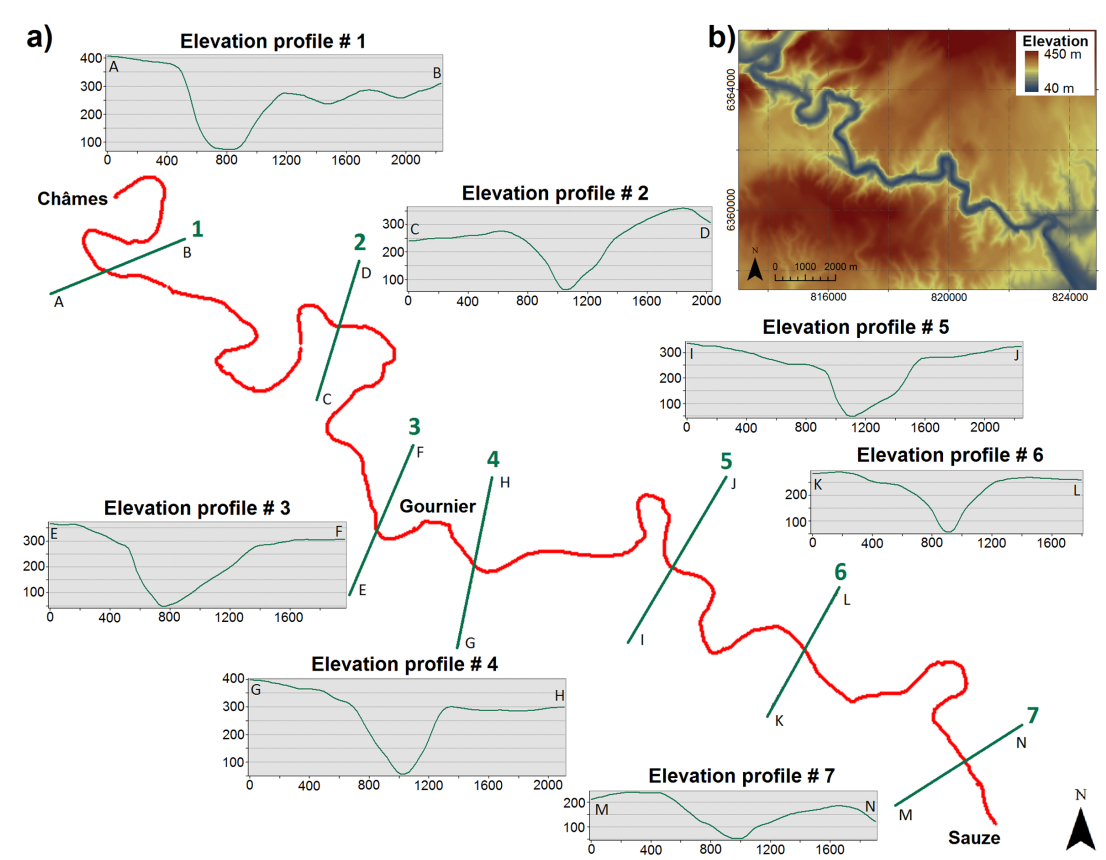

Figure 2. Morphology of the gorges in the river Ardèche depicted by a) transverse profiles, and b) Digital Elevation Model (DEM) extracted from the BD Altiß)(C)IGN Paris)

\section{MATERIAL AND DATA COLLECTION}

\subsection{Pelican Radar}

Pelican radar was fastened on the boat with an adjustable gantry frame (Figure $1 \mathrm{~b}$ ). Pelican radar operates at a frequency of $24 \mathrm{GHz}$, using the FMCW (Frequency Modulated Continuous Wave) technique as described in details in [21, 22]. Its transmitted power is about $50 \mathrm{~mW}$. The radar rotating antenna achieves in one second a complete scan in the horizontal plane around the boat with a maximal range of $100 \mathrm{~m}$. The technical characteristics of Pelican radar are detailed in Table 1.

The radar rotating antenna achieves in one second a complete scan in the horizontal plane in a range of $100 \mathrm{~m}$. A so-called "panoramic radar image" covers 360 degrees around the boat. It is built by the power spectrum computation of the radar signal at each degree of the antenna rotation (see Figure 3). Following FMCW theory, the resulting signal is the mix between the transmitted signal and the signal received from each target. The corresponding beat frequency is then proportional to the radar-target distance and its magnitude depends on the radar reflectivity of the target. The distortions due to the motion of the boat during antenna rotation and speckle effects are corrected. The final map is a $2 \mathrm{D}$ occupancy grid which divides the area of interest in a matrix of $20 \mathrm{~cm} \times 20 \mathrm{~cm}$ cells.

By combining successive panoramic radar images, the R-SLAM algorithm provides step-by-step a global relative 2D map, as reported in [22, 23]. The R-SLAM accuracy is given to be around $50 \mathrm{~cm}$. This algorithm is based on the Simultaneous Localization and Mapping (SLAM) process, widely used in mobile robotic, by which a mobile sensor can build a relative map of its environment and simultaneously computes its relative location within the map. In opposite to classical SLAM algorithms [24, 25], RSLAM algorithm takes into account the whole radar scan and not individual landmarks. The current panoramic image is matched to the global map previously constructed. The maximum of the correlation matrix provides the estimate of the radar displacement (two translations and one rotation) between two 
Table 1. Technical specifications of Pelican radar

\begin{tabular}{|l|l|}
\hline transmitted power & $50 \mathrm{~mW}$ \\
\hline antenna gain & $20 \mathrm{~dB}$ \\
\hline carrier frequency & $24 \mathrm{GHz}$ \\
\hline range & $3-100 \mathrm{~m}$ \\
\hline angular / distance resolution & $1^{\circ} / 1 \mathrm{~m}$ \\
\hline accuracy (on canonical target) & $2 \mathrm{~cm}$ \\
\hline size / weight & $27 \mathrm{~cm} \mathrm{x} 24 \mathrm{~cm} \mathrm{x} \mathrm{30} \mathrm{cm} \mathrm{/} 10 \mathrm{~kg}$ \\
\hline
\end{tabular}

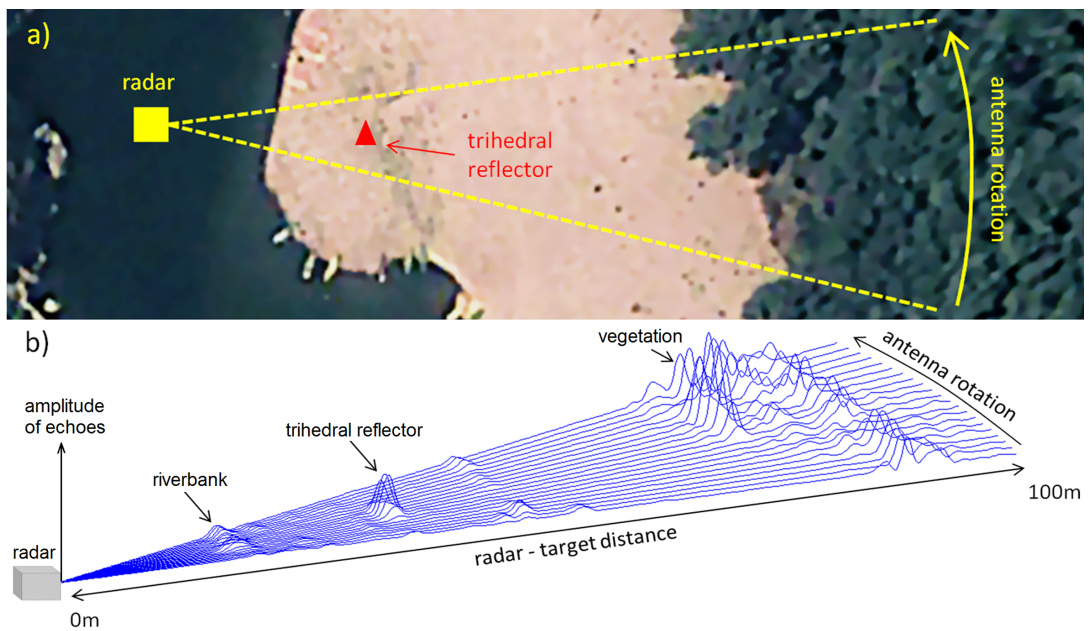

Figure 3. Example illustrating radar data obtained from an angular sector $\left(100 \mathrm{~m} \times 20^{\circ}\right)$ during the second survey. (a) Aerial view of the zone. A trihedral reflector is located in the line of sight of the radar. (b) Corresponding radar spectra (a spectrum at each angular degree). From the radar position, it can be seen successively the echoes from the riverbank, the trihedral reflector and even farther the echoes from the vegetation

scans. Once the inter-scan displacement estimated, the current panoramic radar image is integrated into the global radar map. Thus, the global map is updated after each $360^{\circ}$ scan using a data merging process. The relative R-SLAM trajectory is computed simultaneously from the inter-scans displacements. This trajectory can be very useful to localize when GNSS is inoperative.

Following this principle, the map building is independent of the boat dynamics or of the radar position on the platform. The global radar map is a grey-scale raster with a spatial resolution of $20 \mathrm{~cm}$. The grey-scale level results from the amplitude of the reflected echoes from environment.

The final 2D radar map is georeferenced manually in ArcGIS $₫$ using the reflectors positions, as described in [23]. As the highly reflective metallic trihedra appear as black spots on the radar map, they can be accurately identified on the radar dataset. They are also localized using GNSS. A list of tie points is established both in the radar map (pixel coordinates) and in the real-world coordinates (here, Lambert 93, the French official coordinate system, based on GRS 80 ellipsoid). An affine transformation is then computed to rotate, scale, shift and if necessary shear the radar map, in order to project it into Lambert 93 coordinates. The transformation parameters result from the best fit between the source and destination tie points. The georeferencing RMS error obtained is around $0.7 \mathrm{~m}$. The quality of the georeferencing process may be affected by the accuracy of tie points localization and potential distortions of the radar map. 


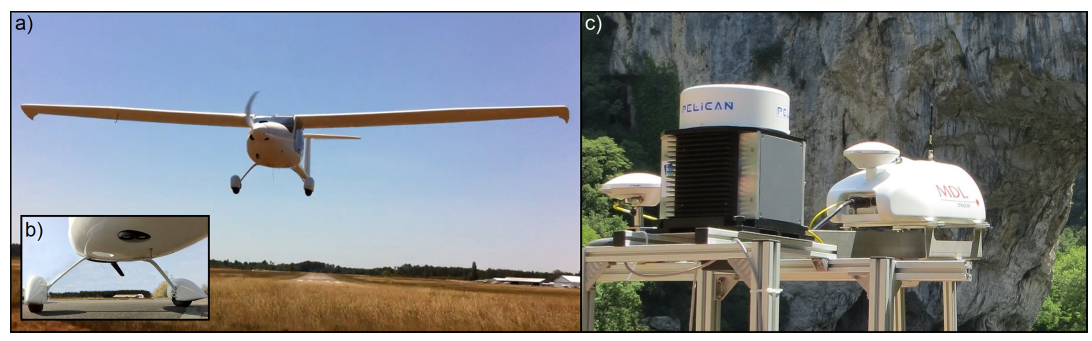

Figure 4. General view of the platforms and devices used during the surveys. (a) Air Infrarouge@ultra-light motorglider (used during the first survey). (b) View of the trapdoor of the sensors below the aircraft. (c) Pelican radar paired with the MLS system on the boat (used during the second survey)

Table 2. Technical specifications of the MLS + IMU unit

\begin{tabular}{|l|l|}
\hline transmitted power & $10 \mathrm{~mW}$ \\
\hline wavelength & $905 \mathrm{~nm}$ (peak) \\
\hline range & up to $250 \mathrm{~m}$ \\
\hline angular / distance resolution & $0.01^{\circ} / 1 \mathrm{c} \mathrm{m}$ \\
\hline laser range accuracy & $5 \mathrm{~cm}$ at $50 \mathrm{~m}$ \\
\hline attitude accuracy (heading / roll / pitch) & $0.1^{\circ} / 0.03^{\circ} / 0.03^{\circ}$ \\
\hline positioning & RTK GNSS receiver \\
\hline size / weight & $68 \mathrm{~cm} \mathrm{x} 26 \mathrm{~cm} \mathrm{x} 24 \mathrm{~cm} / 15 \mathrm{~kg}$ \\
\hline
\end{tabular}

\subsection{Infrared Camera}

The photographic survey has been provided by the company Air Infrarouge $®$ with a motorglider Pipistrel Virus 912 (Figure 4 a). The aircraft flew at $1500 \mathrm{~m}$ altitude. The camera is an Applanix®DSS439, a 39 megapixel airborne imaging system with a $60 \mathrm{~mm}$ focal length. The photographic coverage was on purpose limited to $300 \mathrm{~m}$ on both sides of the river. The collected Color-InfraRed (CIR) images have been ortho-rectified and mosaicked with the Inpho@software. In addition to $20 \mathrm{~cm}$ resolution orthophotos, a DEM is provided by stereorestitution.

CIR images are false colour photographs composed of three bands: Near Infrared (NIR), green and red [26, 27]. Since water absorbs NIR wavelengths energy, clear water appears black in the CIR photograph. Water with varying amounts of suspended particles is depicted as shades of blue. The advantage of CIR imagery is to ensure a high contrast between the stream channel and the riverbanks, and particularly with the riparian forest which appears as red. Dry sand appears white and wet sand appears very light grey or light tan.

\subsection{Laser Scanner}

The laser scanner point cloud has been collected by TopoScanßalong a $2 \mathrm{~km}$ reach from the Pont D'Arc to Châmes (see Figure 1 a). The Dynascan M250@mobile mapping system, detailed in Table 2, was set up on the same gantry frame as the radar (Figure $4 \mathrm{c}$ ).

The GNNS base station was located on the shingle beach of Châmes. As the communication between the base station and the RTK GNSS rover was somewhat uncertain in the northern part of the area, the acquisition by mobile laser scanning has been completed with two stationary laser scans, performed by the Leica Scanstation C5 $®$, on both sides of the Pont d'Arc. The final point cloud counts more than 16 
million of 3D points.

The density of points is governed by the material specificities, by the range between the sensor and the reflected surface and by the speed of the boat. The accuracies of the laser, of the IMU (Inertial Measurement Unit) and of the RTK GNSS receiver determine the final accuracy, about $16 \mathrm{~cm}$ horizontally and $18 \mathrm{~cm}$ vertically at distance of $50 \mathrm{~m}$ from MLS.

\subsection{GNSS Recordings}

Some portions of the canyon are wide enough (about 500-600 m wide) to avoid most of satellite signal obstructions. However, because of the cliffs, the cut-off angle is high and satellites visibility and redundancy are low. This loss of data becomes a problem for the integrity of the position and contributes to higher GDOP (Geometric Dilution Of Precision). We have reported in section 2.B that the positioning accuracy of radar reflectors is above $8 \mathrm{~cm}$ horizontally and $5 \mathrm{~cm}$ vertically. Vertical position errors larger than horizontal errors correspond to VDOP (Vertical Dilution Of Precision) values larger than the HDOP (Horizontal Dilution Of Precision). This effect is a consequence of the high cut-off angle, since the satellites from which we obtained signals were above the receiver.

In addition to shadowing effects, the GNSS signal may be distorted by multipath effects due to signal reflections on the surrounding cliffs [28]. Considering the twisted geometry of the canyon, losses of UHF communications between the GNSS base and the rover are also expected. In such conditions, GNSS localization may be unreliable or even impossible.

The boat-borne GNSS recordings are presented in Figure 5. The trajectory recorded by the boat-borne GNSS receiver appears very fragmented, particularly in steep-sided reaches. It only covers $11 \mathrm{~km}$, i.e. less than $50 \%$ of the whole trajectory. Along the shoreline, the obstruction effects are increased by the nearby cliffs. In this context, it is possible to measure isolated objects, as radar reflectors. But continuous measurements of the land-water interface are unachievable, because of inaccessibility and GNSS losses. In such a context, the topographical configuration and the reach length $(23 \mathrm{~km})$ prevent us from GPS survey of the river shoreline.

On the other hand, the relative R-SLAM trajectory is independent on satellite signal, and so available on the whole study area. The R-SLAM trajectory is georeferenced with the radar map or by matching with the available parts of GNNS trajectory. Once georeferencing is complete, the R-SLAM trajectory provides further information when GNSS receiver fails.

\section{Comparison of the Three Methods in a River Canyon Context}

\subsection{Radar Maps vs. CIR Orthoimages}

As the river banks are mainly covered with vegetation, CIR images give a better contrast than classical RGB images would, in order to delineate the stream channel. Compared to the radar map (Figure $6 \mathrm{~b}$ ) and more generally to ground observations, aerial images offer a synoptic view, allowing a wide ground coverage. The CIR image (Figure 6 a) is quite easy to interpret for the user, as the shapes and the texture are similar to RGB photograph. On the CIR images, water appears as dark blue or almost black. But, very shallow water appears nearly as the material constituting the bottom of the stream due to the high reflectivity of the white calcareous soil. Regarding the radar map, water appears rather uniform. Indeed, on still water the incident wave reflects specularly and so the radar does not receive any echo. But rapids can disturb the laminar flow, creating areas of some turbulent water with small waves. In this case, a 


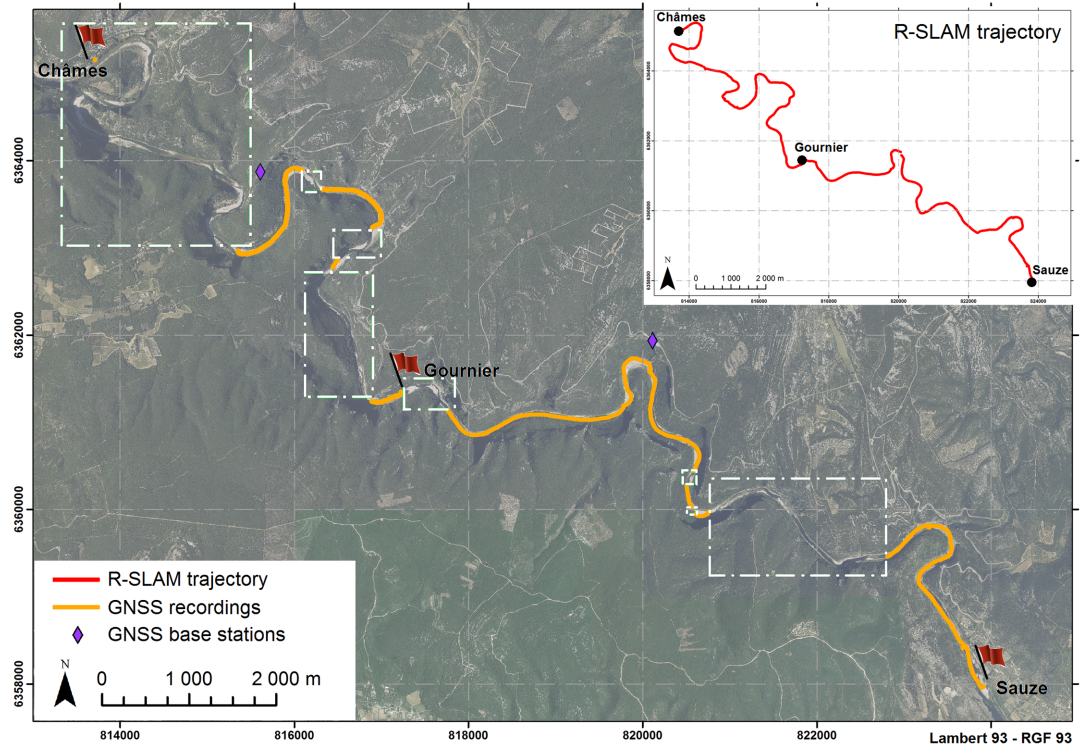

Figure 5. Boat-borne GNSS recordings compared to R-SLAM trajectory from Châmes to Sauze. The GNSS path is represented in yellow. White boxes highlight the zones of GNSS losses. By comparison, the R-SLAM trajectory is shown on the upper-right image

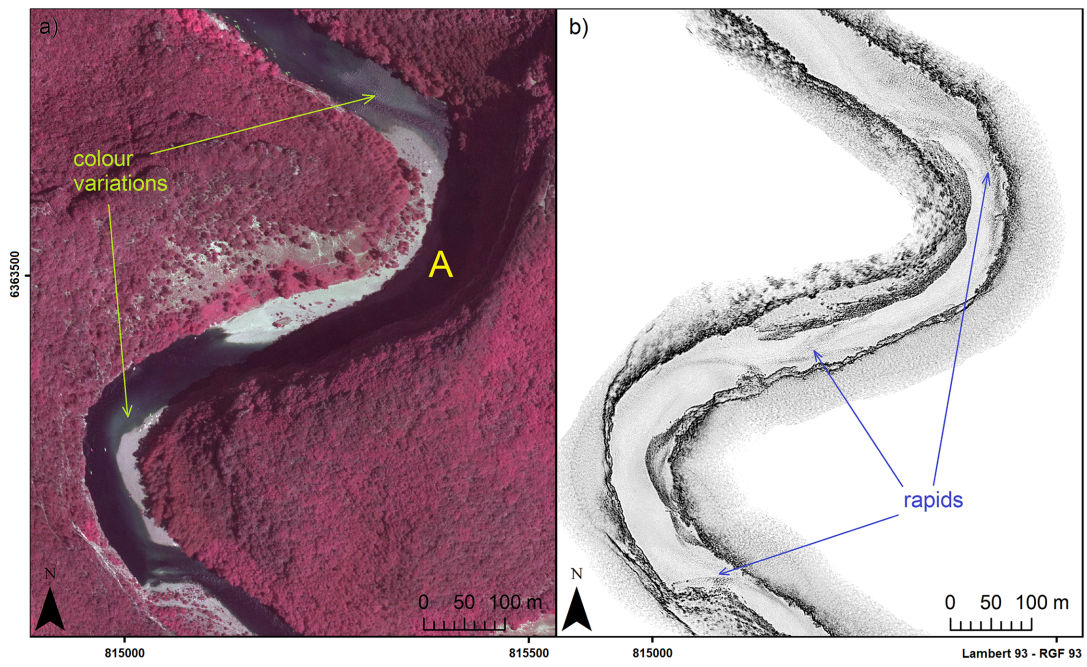

Figure 6. Comparison of (a) the CIR ortho-image and (b) the radar map of a meander of the Ardèche River (1.2 km long). Radar data were collected on the 23 May 2103. CIR photographs were collected on the 27 May 2013

fraction of the incident wave is reflected in the radar's direction ( Figure $6 \mathrm{~b}$ ).

It should be noticed that the mobile objects, such as canoes, are erased from the radar map by the SLAM algorithm. In contrast, the mobile objects appear in the orthoimages.

As shown on Figure 6 a (zone A), in some places it may be difficult to draw the outline of the stream channel because of the shadows of the surrounding cliffs, whereas the radar map is not affected by illumination conditions. The delineation of the stream channel on the radar map is also less affected by the problems of riparian forest or overhanging cliffs hiding the river shoreline.

The stream channel has been digitized manually using ArcGIS(C) software editor. Riverbanks are 

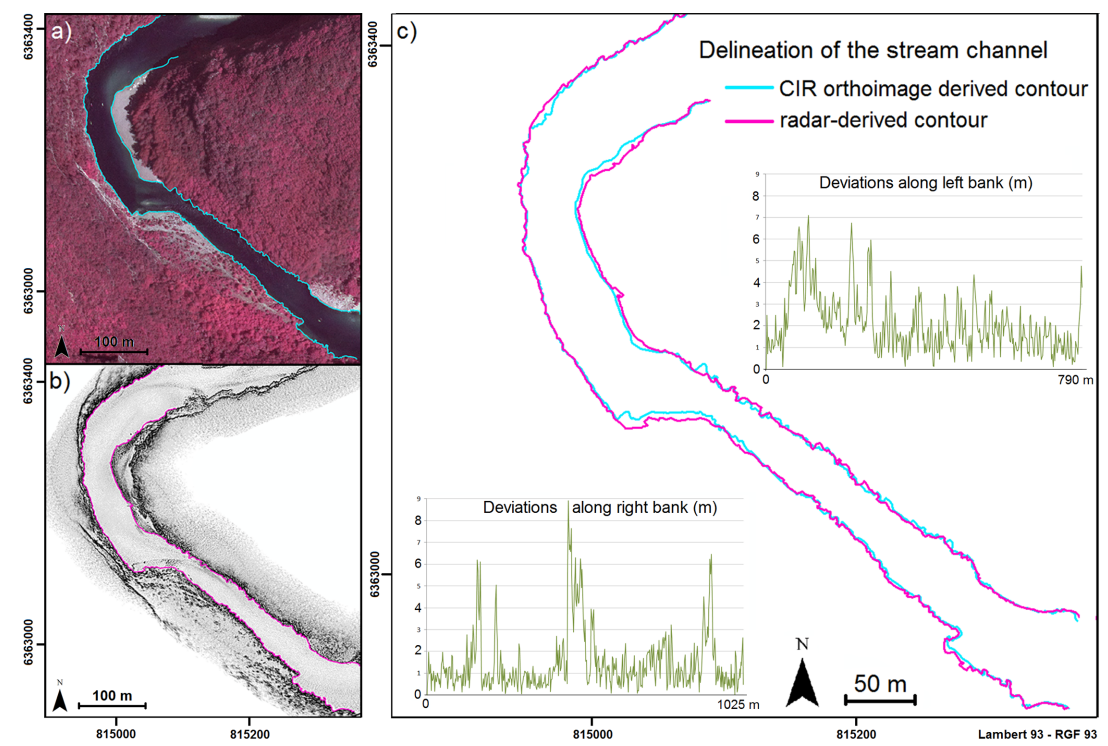

Figure 7. Delineation of the stream channel on an extract of CIR ortho-images (a) and of the radar map (b). Comparison of the position of both contours (c). The deviations between the different contours have been computed along each river banks (see insets). The greatest deviations correspond to beaches where water level decreasing is more visible

digitized with an average resolution of one point each two meters. The relative deviation is computed from the distance between the points of the orthoimage-derived contour and the corresponding points of the radar map-derived contour. This deviation is computed above the unequivocal areas, those which are not affected by shadowing effects (Figure 7). The computed horizontal RMS error is about $2.2 \mathrm{~m}$. It can be thought that this error is mainly due to the decrease in water level between the radar survey (on the 23 May 2013) and the photogrammetric survey (on the 27 May 2013). The greatest deviations are particularly noted along the beaches.

\subsection{Radar Maps vs. Laser Scanning Point Cloud}

Mobile laser scanning allows to monitor the morphology all along the river banks. The major advantage of laser scanning is that it directly measures 3D points with high density (average 3D points density of 60 points $/ \mathrm{m}^{2}$ in this study). As the $905 \mathrm{~nm}$ laser pulses are strongly absorbed by water, laser scanning also appears as a possible solution to accurately delineate stream channels. At first sight, Figure 8 suggests that the delineation of stream channel is very similar between the laser scanner point cloud (Figure 8 a) and the radar map (Figure $8 \mathrm{~b}$ ). Nevertheless, radar data have been collected in only one passage, whereas multiple passages have been necessary to collect laser data covering the entire area. Indeed, the laser system encountered numerous GPS signal losses, preventing data collection. Moreover, laser scanning generally require in post-processing time-consuming manual data cleaning. The final point cloud above the $2 \mathrm{~km}$ long reach represents $610 \mathrm{MB}$ of data.

After computing the relative deviation between the laser scanner-derived contour and the radar mapderived contour (Figure 9), the computed RMS error is about $1.7 \mathrm{~m}$. It should be noticed that merging several point clouds has slightly affected the global precision of the laser survey. 

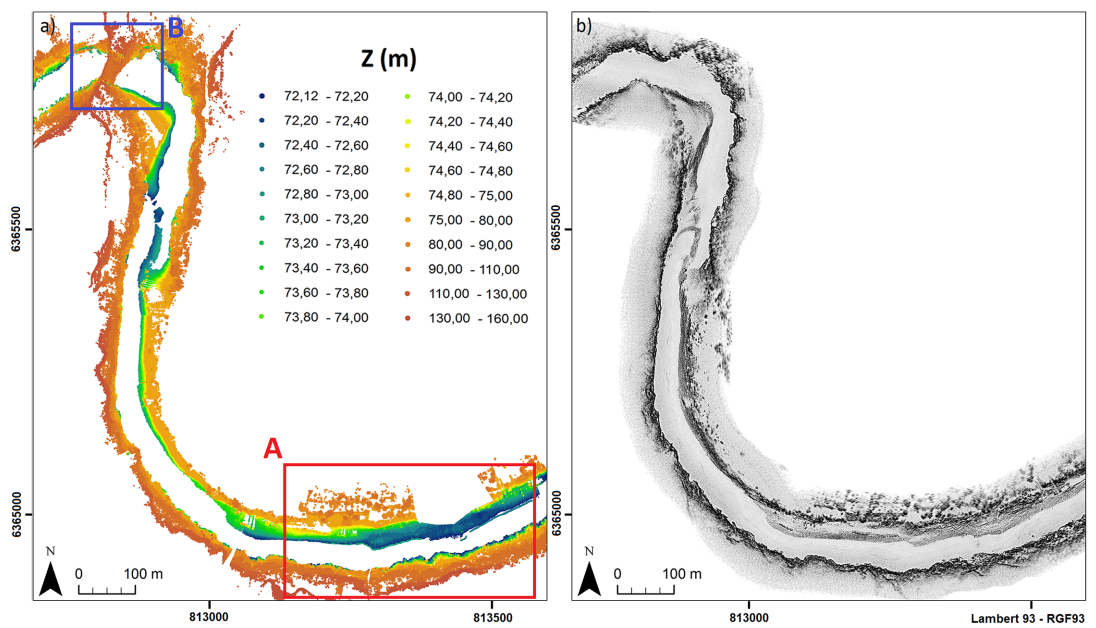

Figure 8. Reach (2 km long) from the Pont d'Arc to Châmes. Extract of the MLS point cloud (a) and of the radar map (b) resulting of the $2^{\text {nd }}$ survey in June 2013. Boxes A and B are detailed in Figure 9 and Figure 10

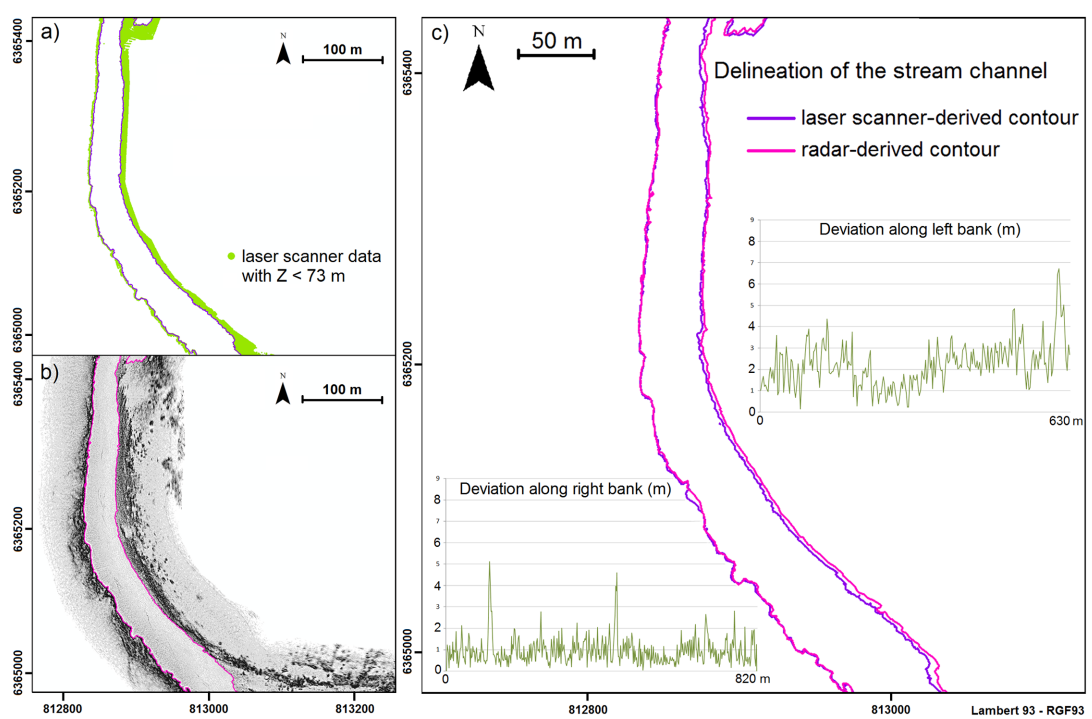

Figure 9. Delineation of the stream channel on an extract (a) of laser scanner point cloud and (b) of the radar map. (c) Comparison of the position of both contours

\section{DISCUSSION}

\subsection{Laser Scanning Artifact}

Figure 10 is a 3D view of a zoom-in on zone A (Figure 8 a). It is apparent from this figure that the mobile laser scanner point cloud presents an abnormality. It can be seen a strip of points about $80 \mathrm{~cm}$ above the water level (in orange on Figure 10) and a second sparser strip situated at the water level (in dark blue on Figure 10).

There is a gap of about 3-4 m between these strips and the shingle beach, creating a gap between contours derived from mobile mapping laser scanner and radar-derived contours. These points do not correspond to anything real. They are independent of the boat trajectory and do not occur outside of box 


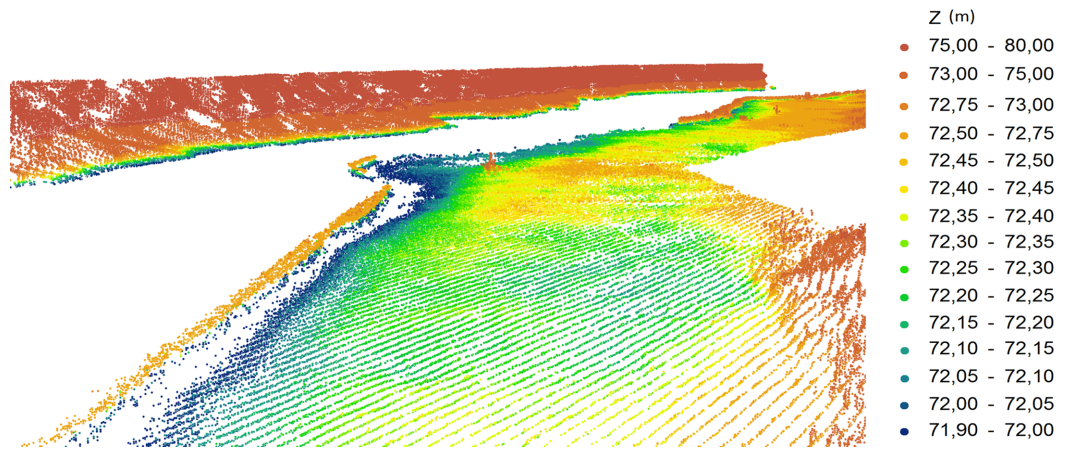

Figure 10. 3D view of a zoom-in on the box A of Figure 6 a showing the artifact on laser scanner data

A. For the moment, we have no comprehensive explanation about this artifact. We suspect it should be due to the texture, shape and color of the scanned surface. [11] mentions that the presence of water may pose significant problems for the interpretation of laser data. They state that partial penetration can occur in clear shallow water with high laser pulse incidence angles and beam refraction off the water surface at reduced incidence angles.

Because of this artifact, laser scanner data cannot be considered as a reference data in our comparison. The deviation between radar-derived contour and laser scanner-derived contour has been computed above an area which is not affected by this anomaly.

\subsection{Effects of the Overhanging Cliffs}

At the north of the area (box B on Figure 8 a), one can notice that the upper part of the arch of Pont d'Arc is not detected by the radar. The arch is an overhanging structure, particularly complex to map. Figure $11 \mathrm{a}, 11 \mathrm{~b}$ and $11 \mathrm{c}$ illustrate how the arch is depicted respectively by the CIR ortho-imagery, by the stereoscopic DEM and by the radar. On the orthophoto (Figure 11 a), only the shadow gives evidence of the presence of an arch. This arch is offset about $5 \mathrm{~m}$ to the East on the ortho-image and on the DEM. It also appears wider on the DEM, as smoothed by the stereorestitution process. Figure $11 \mathrm{~d}, 11 \mathrm{e}$, and $11 \mathrm{f}$ compare radar-derived contours and laser scanner point cloud, which has been sliced at different elevations. $Z=73 \mathrm{~m}$ corresponds to the water surface.

As can be seen from the Figure 11 d, on the northern pier of the arch, the radar map is affected by an overhanging effect, virtually compressing the stream channel. In fact, Figure $11 \mathrm{e}$ shows that, during the rotation of the radar antenna, the northern pier has been scanned up to $85 \mathrm{~m}$ of elevation. This overhanging effect locally causes a $9 \mathrm{~m}$ gap between the radar-derived contour and the laser scanner-derived contour in the delineation of the stream channel.

As the radar echoes are vertically integrated, the asymmetry on the radar map between the northern and the southern pier of the arch is a consequence of the boat trajectory very close to the cliff, as illustrated in Figure $12 \mathrm{a}$ and Figure $12 \mathrm{~b}$.

\subsection{Relevance of Each Technique in a River Canyon Context}

Whatever the remote sensing technique used, most of the comparable studies, especially [13, 14], take place in wide river valleys. The problematic of survey is quite different in a canyon. Thus, the choice 


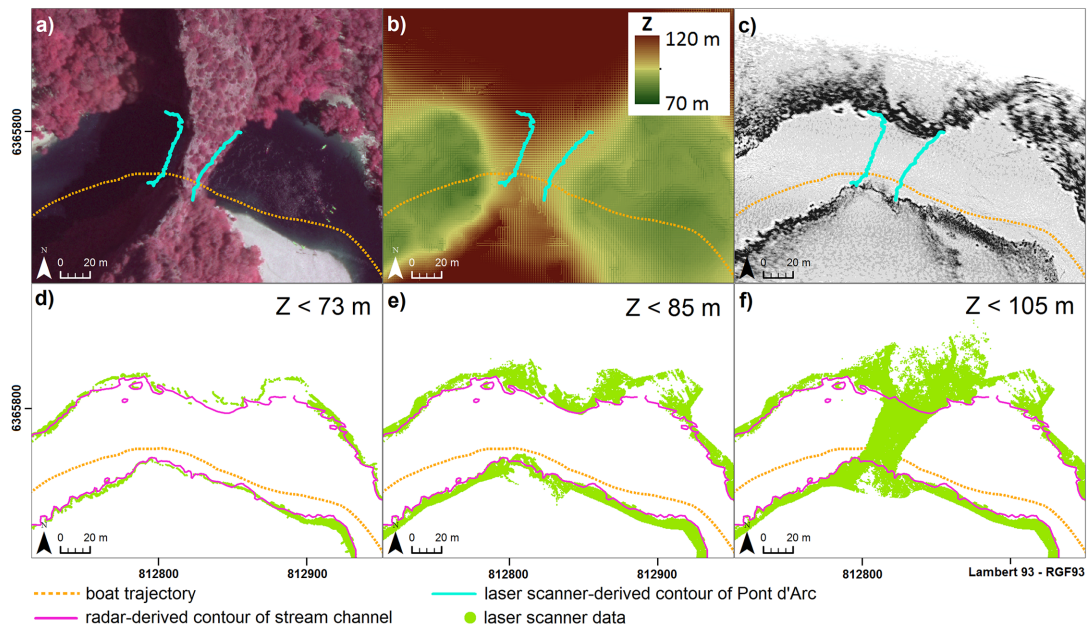

Figure 11. Zoom-in on the box B of Figure 7 a. The laser scanner-derived contour of Pont d'Arc (represented by blue lines) is compared with the position of the Pont d'Arc on (a) CIR orthoimages, (b) the stereoscopic DEM and (c) the radar map. The 2D radar-derived contour of the stream channel (represented by red lines) is compared with slices of the laser scanner point cloud, with (d) $\mathrm{Z}<73 \mathrm{~m}$, (e) $\mathrm{Z}<85 \mathrm{~m}$ and (f) $\mathrm{Z}<105 \mathrm{~m}$

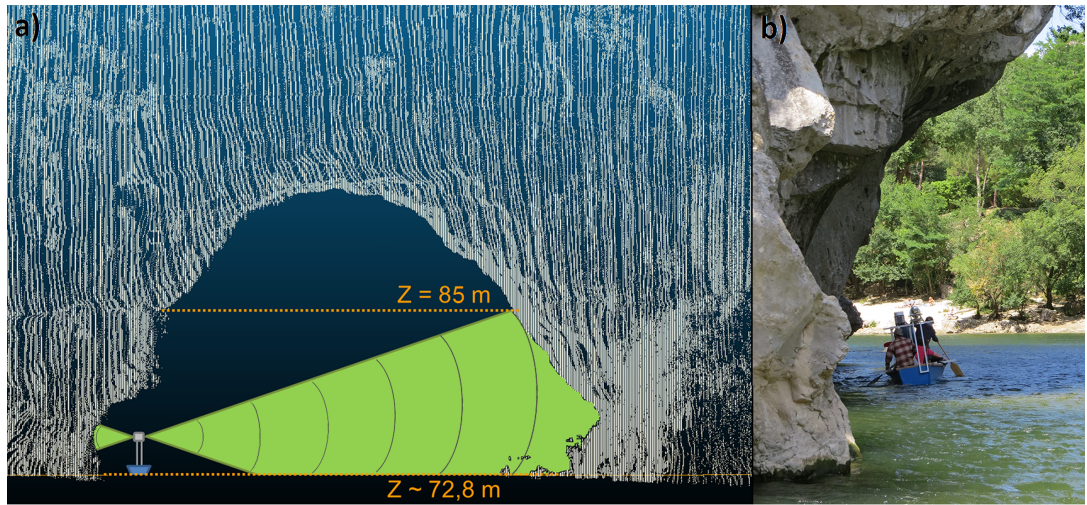

Figure 12. Connection between the route of the boat and the asymmetry of radar scanning. (a) Extract of the laser scan of the Pont d'Arc with a schematic view of the area mapped by the radar beam. (b) The boat trajectory below the Pont d'Arc

of the survey method must firstly consider the constraints imposed by the environment. Surveys with boat-borne sensors are carried out under the riparian tree cover or overhanging cliffs. Nevertheless, even if the boat can sail in shallow water thanks to its small draught, the survey has to be carried out in a navigable river. Satellite signal obstructions are also a problem to address for in-situ survey in gorges.

Aerial photogrammetry offers the advantage of a synoptic view, with a wide ground coverage. Moreover, there is a great archive of aerial photographs, allowing multi-temporal studies [28, 29]. In a practical way, aerial platforms are not affected by the problems of GNNS losses. The images interpretation provides lots of information about land cover of the river's surrounding. A DEM can be generated from stereo-images. In addition of the camera, a GNNS receiver and an IMU are necessary. The operating cost of this technique is very high because of the aircraft chartering. Moreover, the moment of the flyby must be chosen depending on the meteorological and lighting conditions in order to get a good visibility and a minimum of shadowing. It was shown that flying over gorges, the shadowing effects remains important and make ambiguous the delineation of the stream channel. 
Table 3. Relevance of Pelican radar mapping, CIR photogrammetry and mobile laser scanning

\begin{tabular}{|c|c|c|c|}
\hline & Pelican radar mapping & CIR photogrammetry & $\begin{array}{l}\text { Mobile Laser Scan- } \\
\text { ning }\end{array}$ \\
\hline \multicolumn{4}{|l|}{ Material criterion } \\
\hline $\begin{array}{l}\text { necessary additional } \\
\text { equipment }\end{array}$ & gyrometer & DGPS + IMU & DGPS + IMU \\
\hline operating costs & low & high (plane chartering) & low \\
\hline $\begin{array}{l}\text { mode of data collec- } \\
\text { tion }\end{array}$ & boat-borne sensor & flying platform & boat-borne sensor \\
\hline $\begin{array}{l}\text { meteorological re- } \\
\text { liance }\end{array}$ & none & $\begin{array}{l}\text { good flying conditions }+ \\
\text { low cloud cover }\end{array}$ & low humidity \\
\hline $\begin{array}{l}\text { data volume (per } \\
\left.100000 \mathrm{~m}^{2}\right)\end{array}$ & $2 \mathrm{MB}$ & $15 \mathrm{MB}$ & $230 \mathrm{MB}$ \\
\hline \multicolumn{4}{|c|}{ Suitability to delineate stream channel } \\
\hline produced data & 2D radar map & \begin{tabular}{|l|} 
orthoimages + stereo- \\
scopic DEM
\end{tabular} & 3D points clouds \\
\hline shadowing effects & low & high & none \\
\hline overhanging effects & low & high & none \\
\hline appearance of water & uniform except on rapids & $\begin{array}{l}\text { dark blue or black }+ \\
\text { variations in very shal- } \\
\text { low waters }\end{array}$ & no data \\
\hline moving objects & automatically removed & irremovable & manually removed \\
\hline
\end{tabular}

3D laser scanners generally appear as the ideal solution for mobile mapping applications. The strong point of laser scanning system is the ability to directly collect 3D data with additionally high measurement accuracy. It generates a big amount of data (in this case, $230 \mathrm{MB}$ per $100000 \mathrm{~m}^{2}$ ) and involves a timeconsuming manual filtering of data. But, to register scan data, the laser scanner must be supplemented by position and attitude sensors. These sensors raise the purchasing costs of the system and limit its flexibility of use. Indeed, the system is strongly dependent on the proper functioning of the IMU and of the GPS, which is a strong constraint particularly in steep-sided rivers surveying. When the satellite signal is obstructed, data acquisition is interrupted. Moreover, laser scanning can be limited by the meteorological conditions, especially the humidity. [11] also mentions that in certain conditions, the presence of water may be source of errors in laser data. In this study, we have been confronted with such false data.

Even if only providing 2D maps, radar mapping offers the advantage to be very flexible in use. Indeed, it overcomes the limitations of vision-based sensors affected by ambient lighting conditions or weather conditions. It enables a boat-borne survey, avoiding the drawbacks of an aerial survey, and it does not require any GPS, avoiding the problems of signal masking. But, in complex environment, radar reflectors have to be put before the radar scan. For the moment, the acquisitions are restricted to rivers with a limited width (less than $200 \mathrm{~m}$ wide) because of the radar range.

The main results of the comparison are sum up in Table 3.

For laser scanning, [13] recommends multi-angular measurement, i.e. aerial, terrestrial and boat-based survey. From this study, we can add that multi-source surveys are also recommended, particularly in areas where data collection may be problematic. Indeed, the aforementioned techniques are complementary. The redundancy of data collected by the different sensors has allowed us to digitize the whole shoreline, and this despite shadowing effects or GNNS masking. 


\section{CONCLUSION}

Three techniques: i) Pelican radar mapping, ii) aerial CIR-photogrammetry and iii) mobile laser scanning have been tested in order to assess their suitability to delineate the stream channel of a steepsided river. Pointing limitations of the different techniques, the current study demonstrates that there is no unique solution to determine the morphology of the river corridor. The choice of a monitoring technique is primarily dictated by the constraints imposed by the environment. Very few studies focus on monitoring in river gorge context, partly because this type of environment imposes measurements constraints and so is very difficult to survey. Indeed, the remote sensing methods often reach their limits in gorges. To enhance the dataset, the combination of various remote sensing methods is required. Thus, multi-angular and multi-source surveys are greatly recommended for monitoring the whole river canyon.

The adoption of radar surveying opens a number of opportunities, such as allowing in-situ surveys without GNNS and IMU or overcoming the limitations of vision-based sensors affected by ambient lighting conditions or humidity. It appears that radar could be used as a supplement to conventional surveying methods, like aerial photographic monitoring or mobile laser scanning.

A new radar is currently under design. The radar range will be increased up to $200 \mathrm{~m}$, allowing surveys in wider rivers. The antenna beam aperture will be reduced to $2.5^{\circ}$, in order to increase horizontal angular resolution. Further research will focus on identifying the type of riverbanks, using radar reflectance data. For future developments, adding a third dimension to radar mapping would also be an important challenge. Providing information about the cross-sectional area of the stream, 3D mapping of the river corridor may give an important parameter to hydrological modeling.

\section{ACKNOWLEDGMENTS}

This work is part of Pelican Project No. ANR-2010-EMMA-033 supported by the Agence Nationale de la Recherche. The Project was labeled by ViaMeca French pole of competitiveness.

\section{References}

[1] E. Commission, "Water is for life: how the water framework directive helps safeguard Europes resources. Publications Office of the European Union, Luxembourg."

[2] D. L. Higgitt and J. Warburton, “Applications of differential GPS in upland fluvial geomorphology," Geomorphology, vol. 29, no. 1, pp. 121-134, 1999.

[3] J. Brasington, B. Rumsby, and R. McVey, "Monitoring and modelling morphological change in a braided gravel-bed river using high resolution GPS-based survey," Earth Surface Processes and Landforms, vol. 25, no. 9, pp. 973-990, 2000.

[4] W. A. Marcus and M. A. Fonstad, "Remote sensing of rivers: the emergence of a subdiscipline in the river sciences," Earth Surface Processes and Landforms, vol. 35, no. 15, pp. 1867-1872, 2010.

[5] S. Ramasamy, P. Bakliwal, and R. Verma, "Remote sensing and river migration in Western India," TitleREMOTE SENSING, vol. 12, no. 12, pp. 2597-2609, 1991.

[6] B. Notebaert, G. Verstraeten, G. Govers, and J. Poesen, "Qualitative and quantitative applications of LiDAR imagery in fluvial geomorphology," Earth Surface Processes and Landforms, vol. 34, no. 2, pp. 217-231, 2009.

[7] J. Clarke, D. Gibson, and H. Apps, "The use of LiDAR in applied interpretive landform mapping for natural resource management, Murray River alluvial plain, Australia," International Journal of 
Remote Sensing, vol. 31, no. 23, pp. 6275-6296, 2010.

[8] H. C. Jung, J. Hamski, M. Durand, D. Alsdorf, F. Hossain, H. Lee, A. Hossain, K. Hasan, A. S. Khan, and A. Hoque, "Characterization of complex fluvial systems using remote sensing of spatial and temporal water level variations in the Amazon, Congo, and Brahmaputra Rivers," Earth Surface Processes and Landforms, vol. 35, no. 3, pp. 294-304, 2010.

[9] J. Chandler, P. Ashmore, C. Paola, M. Gooch, and F. Varkaris, "Monitoring river-channel change using terrestrial oblique digital imagery and automated digital photogrammetry," Annals of the Association of American Geographers, vol. 92, no. 4, pp. 631-644, 2002.

[10] S. Scherer, J. Rehder, S. Achar, H. Cover, A. Chambers, S. Nuske, and S. Singh, "River mapping from a flying robot: state estimation, river detection, and obstacle mapping," Autonomous Robots, vol. 33, no. 1-2, pp. 189-214, 2012.

[11] G. Heritage and D. Hetherington, "Towards a protocol for laser scanning in fluvial geomorphology," Earth Surface Processes and Landforms, vol. 32, no. 1, pp. 66-74, 2007.

[12] J. Brasington, D. Vericat, and I. Rychkov, "Modeling river bed morphology, roughness, and surface sedimentology using high resolution terrestrial laser scanning," Water Resources Research, vol. 48, no. 11, 2012.

[13] P. Alho, A. Kukko, H. Hyyppä, H. Kaartinen, J. Hyyppä, and A. Jaakkola, “Application of boatbased laser scanning for river survey," Earth Surface Processes and Landforms, vol. 34, no. 13, pp. 1831-1838, 2009.

[14] M. Vaaja, J. Hyyppä, A. Kukko, H. Kaartinen, H. Hyyppä, and P. Alho, "Mapping topography changes and elevation accuracies using a mobile laser scanner," Remote Sensing, vol. 3, no. 3, pp. 587-600, 2011.

[15] G. MacGougan, G. Lachapelle, R. Nayak, and A. Wang, "Overview of GNSS signal degradation phenomena," in Proceedings of the International Symposium on Kinematic Systems in Geodesy (KIS2001)Geomatics And Navigation, Banff, pp. 87-100, 2001.

[16] R. Rouveure, P. Faure, and M.-O. Monod, "Radar Imager for Perception and Mapping in Outdoor Environments," in Advanced Concepts for Intelligent Vision Systems, pp. 618-628, Springer, 2009.

[17] T. Peynot, S. Scheding, and S. Terho, "The marulan data sets: Multi-sensor perception in a natural environment with challenging conditions," The International Journal of Robotics Research, vol. 29, no. 13, pp. 1602-1607, 2010.

[18] N. Sheffer, Y. Enzel, G. Benito, T. Grodek, N. Poart, M. Lang, R. Naulet, and D. Coeur, "Paleofloods and historical floods of the Ardèche River, France," Water Resources Research, vol. 39, no. 12, 2003.

[19] R. Naulet, M. Lang, T. B. Ouarda, D. Coeur, B. Bobée, A. Recking, and D. Moussay, "Flood frequency analysis on the Ardeche river using French documentary sources from the last two centuries," Journal of hydrology, vol. 313, no. 1, pp. 58-78, 2005.

[20] J. Le Coz, A. Hauet, G. Pierrefeu, G. Dramais, and B. Camenen, "Performance of image-based velocimetry (LSPIV) applied to flash-flood discharge measurements in Mediterranean rivers," Journal of hydrology, vol. 394, no. 1, pp. 42-52, 2010.

[21] M. Monod, Frequency modulated radar: a new sensor for natural environment and mobile robotics. PhD thesis, Ph. D. Thesis, Paris VI University, France, 1995.

[22] R. Rouveure, M. Monod, and P. Faure, "Mapping of the environment with a high resolution groundbased radar imager," in Electrotechnical Conference, 2008. MELECON 2008. The 14th IEEE Mediterranean, pp. 822-828, IEEE, 2008.

[23] M. Jaud, R. Rouveure, P. Faure, and M.-O. Monod, "Methods for FMCW radar map georeferencing," ISPRS Journal of Photogrammetry and Remote Sensing, vol. 84, pp. 33-42, 2013.

[24] H. Durrant-Whyte and T. Bailey, "Simultaneous localization and mapping: part I," Robotics \& Automation Magazine, IEEE, vol. 13, no. 2, pp. 99-110, 2006. 
[25] T. Bailey and H. Durrant-Whyte, "Simultaneous localization and mapping (SLAM): Part II," IEEE Robotics \& Automation Magazine, vol. 13, no. 3, pp. 108-117, 2006.

[26] S. Aronoff, Remote sensing for GIS managers. Environmental Systems Research, 2004.

[27] D. P. Paine and J. D. Kiser, Aerial photography and image interpretation. Wiley, 2012.

[28] L. Zanoni, A. Gurnell, N. Drake, and N. Surian, "Island dynamics in a braided river from analysis of historical maps and air photographs," River Research and Applications, vol. 24, no. 8, pp. 1141-1159, 2008.

[29] S. Lane, P. Widdison, R. Thomas, P. Ashworth, J. Best, I. Lunt, G. Sambrook Smith, and C. Simpson, "Quantification of braided river channel change using archival digital image analysis," Earth Surface Processes and Landforms, vol. 35, no. 8, pp. 971-985, 2010. 


\section{About This Journal}

RSP is an open access journal published by Scientific Online Publishing. This journal focus on the following scopes (but not limited to):

3D Technologies

Aerial Photography

$>$ Cartography and Map Publishing

Digital Photogrammetry

$>$ Geoinformatics

$>$ Geo-physics

$>$ Geography

$>$ Global Positioning Systems

$>$ Global Information Systems
Image Compression and Image Processing

Indoor and Wireless Positioning

Light Detection and Ranging

Mobile Mapping System

Natural Hazards

Remote Sensing

Spatial Science

Surveying and Mapping

Visualization

Welcome to submit your original manuscripts to us. For more information, please visit our website: http://www.scipublish.com/journals/RSP/

You can click the bellows to follow us:

$\diamond \quad$ Facebook: https://www.facebook.com/scipublish

$\diamond \quad$ Twitter: https://twitter.com/scionlinepub

$\diamond \quad$ LinkedIn: https://www.linkedin.com/company/scientific-online-publishing-usa

$\diamond \quad$ Google+: https://google.com/+ScipublishSOP

SOP welcomes authors to contribute their research outcomes under the following rules:

$>$ Although glad to publish all original and new research achievements, SOP can't bear any misbehavior: plagiarism, forgery or manipulation of experimental data.

$>$ As an international publisher, SOP highly values different cultures and adopts cautious attitude towards religion, politics, race, war and ethics.

$>\quad$ SOP helps to propagate scientific results but shares no responsibility of any legal risks or harmful effects caused by article along with the authors.

$>$ SOP maintains the strictest peer review, but holds a neutral attitude for all the published articles.

$>\mathrm{SOP}$ is an open platform, waiting for senior experts serving on the editorial boards to advance the progress of research together. 